\title{
Application of antibodies against Borna disease virus phosphoprotein and nucleoprotein on paraffin sections
}

\author{
YING HUANG $^{1,2}$, XIAO-MEI LI ${ }^{1,2}$, SHI-GANG CHEN ${ }^{2}$, JING DENG ${ }^{2,3}$, YANG LEI ${ }^{2,3}$, \\ WEN-JUAN LI ${ }^{2}$, HONG-ZHI ZHANG ${ }^{2,3}$, HONG ZHANG $^{2}$, DAN LI ${ }^{1,2}$ and PENG XIE ${ }^{2,3}$ \\ ${ }^{1}$ Department of Pathology, Faculty of Basic Medicine, Chongqing Medical University; \\ ${ }^{2}$ Neuroscience Center, Key Laboratory of Neurobiology of Chongqing; ${ }^{3}$ Department of Neurology, \\ The First Affiliated Hospital, Chongqing Medical University, Chongqing 400016, P.R. China
}

Received April 9, 2017; Accepted October 30, 2017

DOI: $10.3892 / \mathrm{mmr} .2018 .8467$

\begin{abstract}
In order to study the application of antibodies against recombinant proteins for detecting Borna disease virus (BDV) phosphoprotein (p24) and nucleoprotein (p40) (BDV-p24/p40) on paraffin sections by immunohistochemistry. The purified fusion p24 and p40 proteins were used for the preparation of polyclonal and monoclonal anti-p24 and anti-40 antibodies, which were confirmed by ELISA and western blotting. Paraffin sections were made from BDV-infected Sprague-Dawley (SD) rats $(n=20)$, PBS-injected SD rats $(n=20)$, normal SD rats $(n=20)$ and normal C57 mice $(n=20)$. Immunohistochemical staining was performed according to the EnVision ${ }^{\mathrm{TM}}$ two-step protocol. Heat-mediated antigen retrieval was performed using the retrieval buffer sodium citrate $(1 \mathrm{mM} ; \mathrm{pH} 6.0)$. All the antibodies against recombinant proteins exhibited good sensitivity and specificity. There were significant differences between the BDV-infected group and the BDV-uninfected group for poly- and monoclonal anti-p24 and -p40 antibodies. These antibodies against recombinant proteins may be used effectively to detect BDV p24 and p40 in paraffin sections.
\end{abstract}

\section{Introduction}

Borna disease virus (BDV) is an enveloped, non-segmented negative single-stranded RNA virus, which is highly neurotropic and is able to infect a range of warm-blooded animals, from birds to primates (1-3). Epidemiological investigations

Correspondence to: Professor Dan Li, Department of Pathology, Faculty of Basic Medicine, Chongqing Medical University, 1 Yixueyuan Road, Yuzhong, Chongqing 400016, P.R. China E-mail: lidancq@cqmu.edu.cn

Professor Peng Xie, Department of Neurology, The First Affiliated Hospital, Chongqing Medical University, 1 Yixueyuan Road, Yuzhong, Chongqing 400016, P.R. China

E-mail: xiepeng@cqmu.edu.cn

Key words: Borna disease virus, nucleoprotein, phosphoprotein, monoclonal antibody, polyclonal antibody, immunohistochemistry have demonstrated that neuropsychiatric disorders, including schizophrenia and mood disorders, are associated with BDV infection (4-11). Notably, BDV RNA and antigens have been detected in brain tissues from patients with psychiatric diseases and brain tumors (12-17), in addition to in human lymphocytes (18).

The genome of BDV, at a length of $8.9 \mathrm{~kb}$, consists of six open reading frames which respectively encode six proteins (19). Among these proteins, phosphoprotein (BDV p24) and nucleoprotein (BDV p40) are frequently detected together in human serological studies (20-23); therefore, they were selected as the primary target antigens in the present study.

There are four principal methods of detecting BDV infection: i) Isolating virus from blood samples or tissue homogenate $(5,8,14)$; ii) detecting BDV-RNA with reverse transcription-polymerase chain reaction (RT-PCR) analysis (24); iii) serological testing, including indirect immunological fluorescence assays (25), western blotting $(26,27)$ and ELISA (7); and iv) detecting the primary antigens (p24 or/and p40) via immunohistochemical staining in situ (28). The first three methods require fresh specimens. Although serum or plasma samples are the easiest diagnostic sources, in clinical practice, pathological tissue from patients undergoing brain surgery has may be fixed and embedded into paraffin blocks for long-term preservation in pathology laboratories, which also are favorable materials for use in screening for BDV infection in the population via immunohistochemistry. Previous studies have used antibodies donated from other collaborating laboratories $(29,30)$. However, there are no commercially available anti-BDV protein antibodies.

Monoclonal and polyclonal anti-p24 and anti-p40 antibodies have been prepared previously by animal immunization technology and hybridoma technology (31). Therefore, the primary purpose of the present study was to examine the application of the constructed antibodies against recombinant proteins for detecting p24 and p40 in paraffin sections of BDV-infected rat/mouse brain tissue by immunohistochemical staining (including appropriate dilutions, antigen retrieval and evaluation of the results). The present study may provide a foundation for detecting BDV infection in brain tissue paraffin sections, particularly from brain tumors, by immunohistochemistry $(12,14)$. 


\section{Materials and methods}

$B D V$ strain. Human BDV strain $\mathrm{Hu}-\mathrm{H} 1$ was isolated from the blood cells of a severely depressed patient with bipolar disorder in Germany, and co-cultured with a permanent human oligodendrocyte (OL) cell line (5). BDV-Hu-H1 (kindly supplied by Professor Hanns Ludwig, Free University of Berlin, Berlin, Germany) virus solution was obtained by repeated freezing and thawing of BDV-infected OL cells and stored at $-80^{\circ} \mathrm{C}$.

\section{Viral infection}

Infection of animals. Sprague-Dawley (SD) rats born within $24 \mathrm{~h}$ were intracranially inoculated in their right cerebral hemispheres with either: i) $30 \mu \mathrm{l} \mathrm{Hu}-\mathrm{H} 1$ virus solution $\left[10^{4}\right.$ focus forming units/ml; n=20; 11 males, weight (305 \pm 12 g); 9 females, weight $(217 \pm 15 \mathrm{~g})$ ], as previously described (32); or ii) PBS [30 $\mu \mathrm{l}$; negative control; $\mathrm{n}=20$; males, weight $(313 \pm 14 \mathrm{~g}) ; 12$ females, weight (222 $\pm 12 \mathrm{~g})$ ]. In addition, $20 \mathrm{SD}$ rats without injection [10 males, weight $(310 \pm 12 \mathrm{~g}) ; 10$ females, weight $(224 \pm 10 \mathrm{~g})]$, and 20 uninjected C57 mice [11 males, weight ( $23 \pm 1 \mathrm{~g})$; 9 females, weight $(20 \pm 1 \mathrm{~g})]$ as the normal control. Rats and mice were group-housed under a 12-h light/dark cycle (on between 7:00 a.m. and 7:00 p.m.) with unrestricted access to food and water at a constant room temperature of $22-24^{\circ} \mathrm{C}$ and $50 \%$ humidity. All animals that we used in this experiment were provided by the Experimental Animal Center at Chongqing Medical University (Chongqing, China). All the procedures performed in the present study were approved by the Ethics Committee of Chongqing Medical University (Chongqing, China).

Preparation of samples. All rats and mice were sacrificed on postnatal day 56. Each right brain hemisphere was collected and stored at $-80^{\circ} \mathrm{C}$. The total protein was extracted from the right brain tissue from the $-80^{\circ} \mathrm{C}$ refrigerator $(n=20)$ using the Total Protein Extraction kit (Nanjing KeyGen Biotech Co., Ltd., Nanjing, China). The protein concentrations were determined with an Enhanced Bicinchoninic Acid Protein Assay kit (Beyotime Biotechnology Co., Ltd., Zhejiang, China). Protein samples (15 $\mu \mathrm{g}$ per lane) were subjected to SDS-PAGE on a $12 \%$ gel $\left(100 \mathrm{~V}\right.$ for $2 \mathrm{~h}$ ) following heat denaturing at $95^{\circ} \mathrm{C}$ for $5 \mathrm{~min}$. Proteins were electrophoretically transferred to polyvinylidene fluoride (PVDF) membranes (100 V for $75 \mathrm{~min})$ and were blocked in $5 \%$ non-fat dried milk for $1 \mathrm{~h}$ at room temperature. The membranes were incubated overnight at $4^{\circ} \mathrm{C}$ with mouse anti-BDV nucleoprotein (p24) monoclonal antibody (1:5,000; kindly provided by Professor Hanns Ludwig) $(31,32)$ and used anti-GAPDH antibody (1:5,000; ab9485, Abcam, Cambridge, UK) served as the loading control. The membranes were washed with TBS-Tween 20 (TBST), and further incubated with goat anti-mouse immunoglobulin (Ig)G-HRP (1:10,000; bs-0296G-HRP, Beijing Bioss Co., Ltd., Beijing, China) at room temperature for $2 \mathrm{~h}$. Subsequent to washing the membranes, the protein bands were visualized using enhanced chemiluminescence detection reagents (Nanjing KeyGen Biotech Co., Ltd.). The signal was detected using the Bio-Rad ChemiDoc XRS system (Bio-Rad Laboratories, Inc., Hercules, CA, USA).

\section{Preparation of antibodies}

Preparation of antigens. Full-length cDNAs of BDV p24 and p40 were generated using the RT-PCR (33). The PCR conditions were: An initial denaturation at $94^{\circ} \mathrm{C}$ for $5 \mathrm{~min} ; 30$ cycles of $94^{\circ} \mathrm{CC}$ for denaturation $(40 \mathrm{sec})$, annealing at $60^{\circ} \mathrm{C}$ (40 sec) and elongation at $72^{\circ} \mathrm{C}(30 \mathrm{sec})$; and extension at $72^{\circ} \mathrm{C}$ for $5 \mathrm{~min}$. Total RNAs isolated from BDV-Hu-H1-infected OL cells were used as templates. The primers used for RT-PCR were: 5'-TAACATATGACCATGCCACCCAAGAGACGC-3' (forward) and 5'-CGCGGATCCAAGTTTAGACCAGTC ACAC-3' (reverse) for p40; and 5'-CCGCATATGGCAACG CGACCATCGAGT-3' (forward) and 5'-CCGCTCGAGTGG TATGATGTCCCATTCATCC-3' (reverse) for p24. The cDNAs of p24 and p40 were ligated into the vectors (Novagen; Merck KGaA, Darmstadt Germany) pET-41a by NdeI and XhoI sites and pET-14b by NdeI and BamHI sites, respectively. These vectors were transformed into Escherichia coli BL21 (DE3; the Key Laboratory of Neurobiology, Chongqing, China). The authenticity of the expression constructs was verified by sequencing. The recombinant histidine-tagged p24 and p40 proteins were used following purification using HisTrap HP (GE Healthcare, Chicago, IL, USA) column chromatography. The column was equilibrated with equilibration buffer and the bacterial lysate was filtered to obtain the supernatant, which was purified via a purification column. Unbound hybrid proteins were removed to obtain recombinant proteins by using wash buffer containing $20 \mathrm{mmol} / 1$ Tris- $\mathrm{HCl}(\mathrm{pH} \mathrm{8.0)}$, $50 \mathrm{mmol} / \mathrm{l}$ imidazole and $500 \mathrm{mmol} / \mathrm{l} \mathrm{NaCl}$.

Polyclonal antibody preparation. Two adult male New Zealand white rabbits with the weight of $3 \mathrm{~kg}$ obtained from the Experimental Animal Center of Chongqing University were used for the experiment. Under specific pathogen-free conditions at a constant room temperature of $22-24^{\circ} \mathrm{C}$ and $50 \%$ humidity with a 12-h light/dark cycle (lights on: 8:00 a.m., off: 8:00 p.m.) and provided ad libitum access to food and water. The purified histidine-tagged p24 protein (500 $\mu \mathrm{g}$ diluted with $1 \mathrm{ml}$ of physiological saline), was emulsified with an equal volume of complete Freund's adjuvant (Sigma-Aldrich, Merck $\mathrm{KGaA}$ ) and injected intradermally into a rabbit over 10 to 12 sites. Following pre-immunization blood drawing, the rabbit received booster injections twice, at monthly intervals, with the same amount of protein mixed with incomplete Freund's adjuvant. Subsequent to the third injection, the serums were collected and purified by antigen immunoaffinity chromatography. The antibody against recombinant p40 was similarly produced. The activated agarose gel and antigen were coupled overnight to prepare an antigen-immobilized column. The closed column was pre-washed with PBS to equilibrate the column. Following, the serums were added to a well-balanced column and incubated overnight at $4^{\circ} \mathrm{C}$ and washed with the eluate to obtain purified antibody. The eluent was measured at $280 \mathrm{~nm}$.

Monoclonal antibody preparation. A total of $5 \mathrm{BALB} / \mathrm{c}$ mice [female, 6-8 weeks old, weight $(21 \pm 1 \mathrm{~g})$ ] were obtained from the Experimental Animal Center of Chongqing Medical University. Under specific pathogen-free conditions at a constant room temperature of $22-24^{\circ} \mathrm{C}$ and $50 \%$ humidity with a 12 h light/dark cycle (lights on: 8:00 a.m., off: 8:00 p.m.) and provided ad libitum access to food and water. The mice were first immunized intraperitoneally with histidine-tagged p24 protein $(50 \mu \mathrm{g}$ diluted with $100 \mu \mathrm{l}$ saline, emulsified in Freund's 
complete adjuvant). Immunization was repeated three times at intervals of 2 weeks. Hybridoma was prepared by fusing SP $2 / 0$ myeloma cells (Nanjing GenScript Co., Ltd., Nanjing, China) and spleen cells of immunized BALB/c mice. Immunized mouse spleen cells and SP2/0 myeloma cells were hybridized with 50\% PEG 4000 (Sigma-Aldrich Merck KGaA) at a 5:1 ratio and cultured in RPMI-1640 culture medium (Hyclone; GE Healthcare Life Sciences, Logan UT, USA). The recombinant BDV nucleus protein was used as the antigen, and the positive cell clone strains were measured by indirect ELISA (Cosmo ELISA Plate, 1105-096; Cosmo Biosciences, Inc., San Diego, CA, USA). The optical density (OD) of each well was measured at $450 \mathrm{~nm}$. The criteria were as follows: OD was greater than or equal to $2.1 \mathrm{X}$ the negative control. Candidates with positive ELISA clones were subjected to limited dilution and further clones were screened. The hybridoma cell strains with stable secretory monoclonal antibody were determined by the limited dilution method for three-times sub clones with the preliminary screening of the suspected positive cell clones: The selected positive cell clones ( 1 cell/well) were seeded into a 96-well plate in HT medium (Hyclone; GE Healthcare Life Sciences) and were cultured for 4 weeks. The supernatant was then collected and detected via indirect ELISA, which was used until the positive rate was $100 \%$. For the production of large amounts of monoclonal antibodies, mouse ascites of monoclonal antibodies were collected and purified by protein G affinity chromatography. Firstly, a purification column containing Sepharose-protein $\mathrm{G}$ was washed with binding buffer. Secondly, mouse ascites were diluted 4 times with binding buffer, and centrifuged at $11,900 \mathrm{xg}$ for $30 \mathrm{~min}$ at $4^{\circ} \mathrm{C}$. Thirdly, the supernatant was added into the washed purification column. The bound monoclonal antibodies were eluted with elution buffer and loaded in a collection tube containing $0.1 \mathrm{ml}$ potassium phosphate buffer. Finally, the eluent was measured at A280 $\mathrm{nm}$. The antibody against the recombinant p40 was similarly produced.

\section{Titer and specificity of antibodies}

Titer detection by ELISA. The recombinant proteins were diluted to a concentration of $100 \mathrm{ng} / 100 \mu \mathrm{l}$ with $0.05 \mathrm{~mol} / \mathrm{l}$ $\mathrm{Na}_{2} \mathrm{CO}_{3}-\mathrm{NaHCO}_{3}$ coating buffer ( $\mathrm{pH}$ 9.6) and were added to 96-well plates (100 $\mu 1$ proteins/well). Following overnight incubation at $4^{\circ} \mathrm{C}$, plates were washed with PBS-Tween 20 (PBST) three times. Wells were blocked with $5 \%$ bovine serum albumin (Hyclone; GE Healthcare Life Sciences) solution for $1 \mathrm{~h}$ at $37^{\circ} \mathrm{C}$ and washed with PBST three times. The pre-immunization serum was diluted 1:1,000 and the purified antibodies were diluted 1:1,000, and serially diluted two-fold from 1:1,000 to $1: 512,000$. The plates were incubated with $100 \mu \mathrm{l}$ diluted antibodies for $1 \mathrm{~h}$ at $37^{\circ} \mathrm{C}$. Wells were washed and further incubated with goat anti-rabbit immunoglobulin $\mathrm{G}$ antibody (Beijing Bioss Co., Ltd.) diluted 1:2,500 (100 $\mu \mathrm{l} /$ well), conjugated with horseradish peroxidase (HRP). Following washing of the plates, 3,3,5,5,-tetramethylbenzidine was added to each well. The chromogenic reaction was stopped by $50 \mu \mathrm{l} /$ well $2 \mathrm{~mol} / 1 \mathrm{H}_{2} \mathrm{SO}_{4}$ following a 10 -min incubation at $37^{\circ} \mathrm{C}$. The optical density of each well was measured at $450 \mathrm{~nm}$. All samples were run in triplicate. PBS was used as a blank control and the pre-immunization serum was used as a negative control.

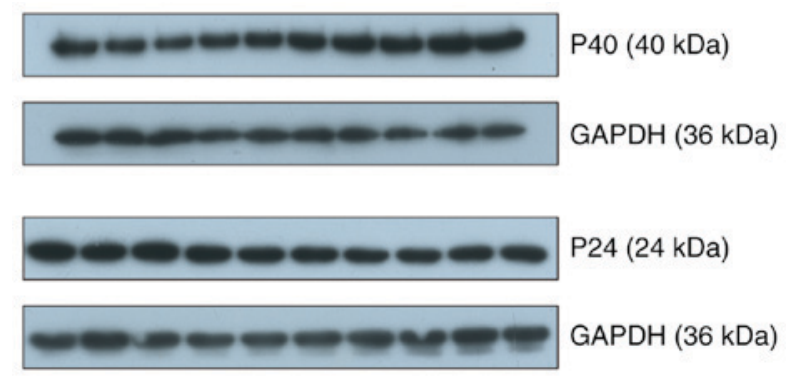

Figure 1. Western blot analysis of viral infection of Borna disease virus-injected rats. The protein for western blot was from the right brain hemisphere. The dilution of the monoclonal anti-p24 antibody was 1:5,000. p40, Borna disease virus nucleoprotein; p24, Borna disease virus phosphoprotein.

Specificity identification by western blotting. Proteins were extracted from normal OL cells and BDV-infected OL cells using the KeyGen Whole Cell Lysis Assay (Nanjing KeyGen Biotech Co., Ltd.). Protein concentrations were quantified according to the Bradford procedure (Bradford protein quantitation assay; Nanjing KeyGen Biotech Co., Ltd.) to maintain the same loads. Proteins (normal OL cells lysates, $25 \mu \mathrm{g}$; BDV-infected OL cell lysates, $25 \mu \mathrm{g}$; recombinant p24 and p40 BDV proteins, $1 \mu \mathrm{g}$ ) were separated by $12 \%$ SDS-PAGE (100 V for $2 \mathrm{~h}$ ) following heat denaturation at $95^{\circ} \mathrm{C}$ for $5 \mathrm{~min}$, and transferred onto PVDF membranes in Tris-glycine buffer containing $20 \%$ methanol $(100 \mathrm{~V}$ for $75 \mathrm{~min}$ ). The membranes were stripped according to marker bands and were blocked in 5\% non-fat milk at room temperature for $1 \mathrm{~h}$. The primary antibodies $(1: 1,500)$ were diluted with blocking buffer and incubated with membranes overnight at $4^{\circ} \mathrm{C}$. The membranes were washed with TBST, and further incubated with HRP-conjugated secondary antibodies (1:2,000; bs-0295G-HRP and bs-0296G-HRP, Beijing Bioss Co., Ltd.) at room temperature for $2 \mathrm{~h}$. Following washing of the membranes, the protein bands were visualized using enhanced chemiluminescence detection reagents (Nanjing KeyGen Biotech Co., Ltd.). The signal was detected using the Bio-Rad ChemiDoc XRS system (Bio-Rad Laboratories, Inc.). Additionally, the isolated recombinant BDV proteins by $12 \%$ SDS-PAGE were stained with Coomassie brilliant blue at room temperature for $3 \mathrm{~h}$ and then scanned by Epson Graphic Arts Scanner. The OD of each band was semi-quantified using Quantity One software (version 4.4.0; Bio-Rad Laboratories, Inc.).

\section{Immunohistochemical analysis}

Paraffin section preparation. All rats and mice were sacrificed on postnatal day 56. All left-brain hemispheres were fixed with $4 \%$ paraformaldehyde at room temperature for $24 \mathrm{~h}$ and embedded in paraffin. Tissue section was sliced along the sagittal plane into $5-\mu \mathrm{m}$ sections, for the purpose of immunohistochemical staining.

All tissue sections from BDV-infected rats $(n=20)$, PBS-injected rats $(n=20)$, normal SD rats $(n=20)$ and normal C57 mice $(n=20)$ were tested with four antibodies against recombinant proteins respectively: Poly- and monoclonal anti-p24 antibodies (pAbp24 and mAbp24), and poly- and monoclonal anti-p40 antibodies (pAbp40 and mAbp40). All primary antibodies (pAbp24, mAbp24, pAbp40 and mAbp40) 

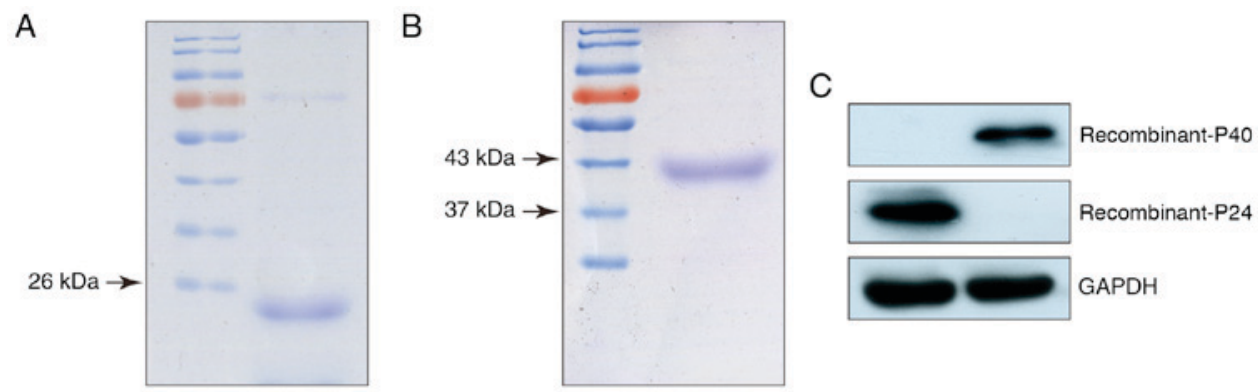

Figure 2. Purification of recombinant $\mathrm{p} 24$ and $\mathrm{p} 40$ and verification by western blotting. The protein bands were stained with Coomassie brilliant blue. A single protein band is presented for (A) p24 and (B) p40, and the purity of p24 and p40 was 85 and 90\%, respectively. (C) His-p24 and his-p40 were detected by monoclonal antibodies and the reaction bands were observed at 24 and $40 \mathrm{kDa}$. p40, Borna disease virus nucleoprotein; p24, Borna disease virus phosphoprotein.
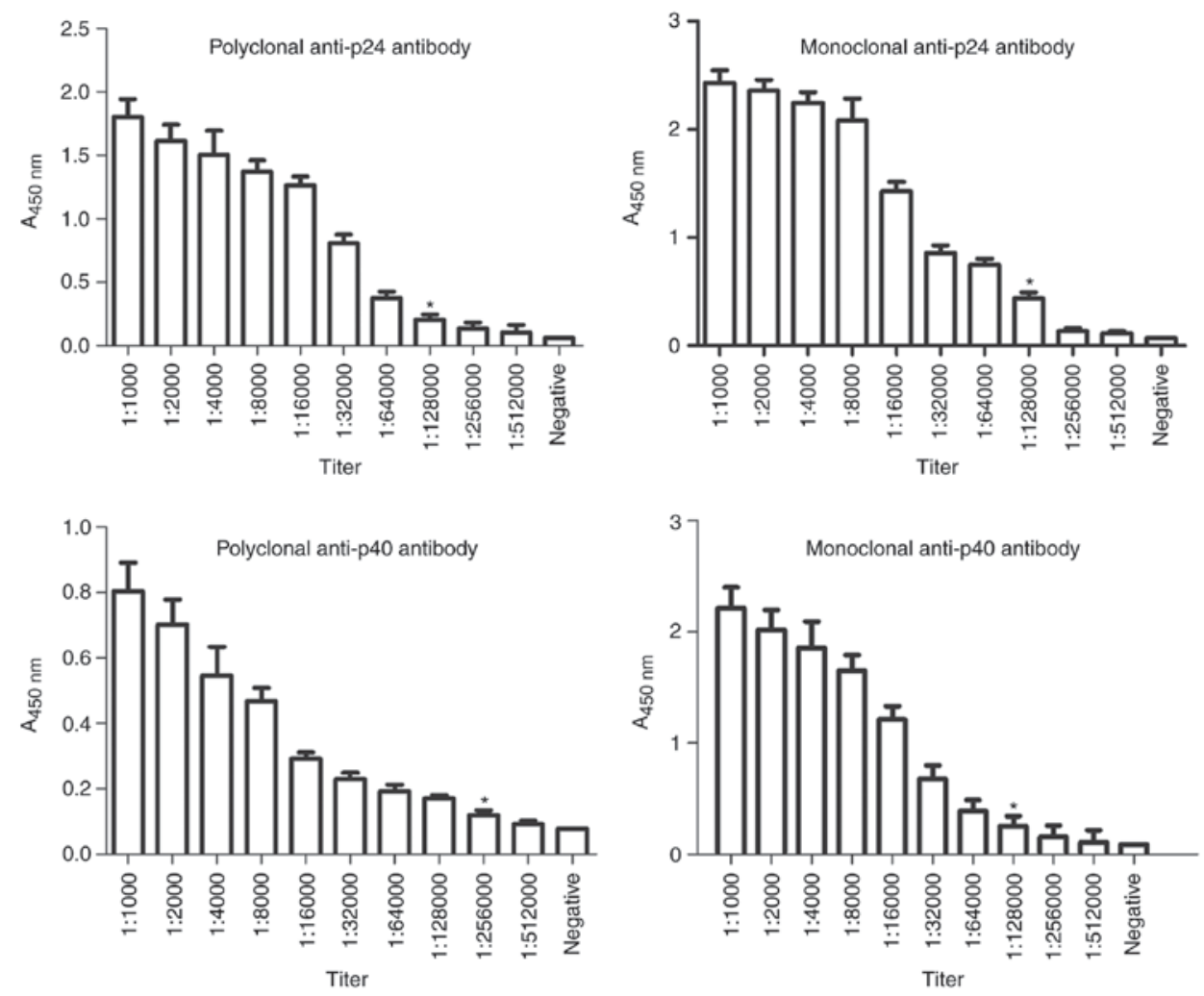

Figure 3. Titer of each antibody, detected by ELISA analysis. The serial dilution of each antibody was from 1:1,000 to 1:512,000. 3,3',5,5'-tetramethylbenzidine was used as the chromogenic reagent. $\mathrm{A}_{450 \mathrm{~nm}}$ was measured. Absorbance ratios of results with antibodies to results with pre-immunization serum $>2.1$ were considered to be positive titers. " , minimal positive titer. $\mathrm{A}_{450 \mathrm{~nm}}$, absorbance at $450 \mathrm{~nm}$; p40, Borna disease virus nucleoprotein; p24, Borna disease virus phosphoprotein.

were diluted 1:50, 1:100, 1:200, 1:400, 1:600, 1:800, 1:1,000, 1:1,200, 1:1,400, 1:1,600, 1:1,800, 1:2,000 and 1:5,000.

Immunohistochemical staining. The technique of detection of BDV in the brain by immunohistology was pioneered by Gosztonyi et al (34). Immunohistochemical staining was performed according to the EnVision two-step protocol (EnVision $^{\mathrm{TM}}$; Dako; Agilent Technologies, Inc., Santa Clara, CA, USA). Varying concentrations of alcohol used for rehydration were as follows: Two washes with absolute ethanol $3 \mathrm{~min}, 95 \%$ ethanol $3 \mathrm{~min}, 85 \%$ ethanol $3 \mathrm{~min}$ and $80 \%$ ethanol $3 \mathrm{~min}$. Heat-mediated antigen retrieval was performed within 3 min using retrieval buffer sodium citrate $(1 \mathrm{mM} ; \mathrm{pH} 6.0)$ with a pressure cooker. Then the slices were washed with PBS for 3 min, three times and blocked with $3 \%$ hydrogen peroxide at room temperature for $10 \mathrm{~min}$. The primary antibodies were incubated overnight at $4^{\circ} \mathrm{C}$ and the blank control was treated with PBS instead of primary antibody, overnight at $4^{\circ} \mathrm{C}$. Following incubation with HRP-conjugated secondary antibody (K406511-2, EnVision $^{\mathrm{TM}}$; Dako; Agilent Technologies, Inc.) at room temperature for $30 \mathrm{~min}$, the sections were stained with diaminobenzidine for a few sec and counterstained with hematoxylin for $3 \mathrm{~min}$ at room temperature.

Evaluation criteria. The present study focused on the evaluation of the intensity of positive staining, positive proportion of neurons and neuroglial cells and background staining in three 


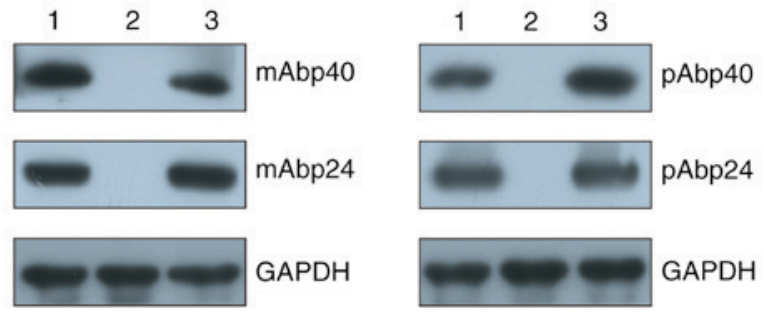

Figure 4. Specificity of antibodies, detected by western blotting. Secondary antibodies were conjugated with horseradish peroxidase. The protein bands were visualized by enhanced chemiluminescence. Lane 1, lysate of BDV-infected OL cells; lane 2, lysate of normal OL cells; lane 3, recombinant proteins. pAbp24, polyclonal anti-p24 antibody; mAbp24, monoclonal anti-p24 antibody; pAbp40, polyclonal anti-p40 antibody; mAbp40, monoclonal anti-p40 antibody. p40, Borna disease virus nucleoprotein; p24, Borna disease virus phosphoprotein.
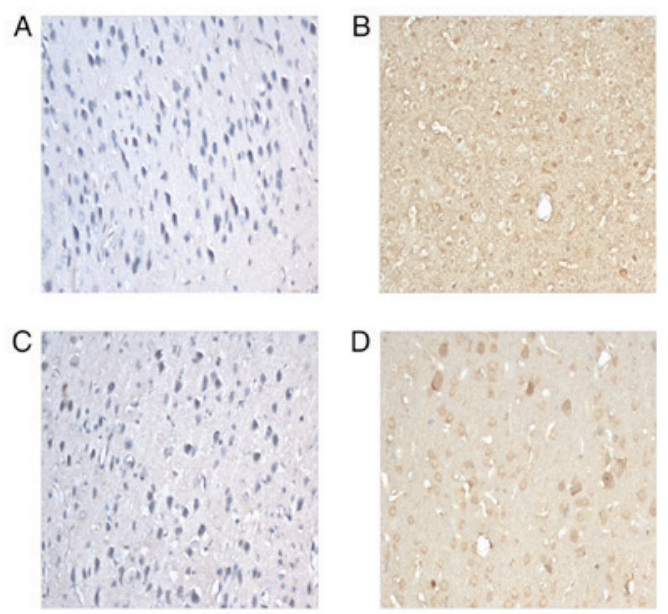

Figure 5. Immunohistochemical staining of BDV p24 protein in rat brain tissues (magnification, x200). Horseradish peroxidase-conjugated secondary antibodies and diaminobenzidine were used. Primary antibodies were diluted 1:200. (A) Negative results of tissue staining with pAbp24 from PBS-injected rats; (B) positive staining of tissue from the BDV-infected group with pAbp24, demonstrating that protein p24 was prominently expressed in the cytoplasm of neuronal and glial cells; (C) negative results of tissue staining with mAbp24; (D) positive staining of tissue from the BDV-infected group with mAbp24, demonstrating that protein $\mathrm{p} 24$ was prominently expressed in the cytoplasm of neuronal and glial cells. BDV, Borna disease virus; pAb, polyclonal antibody; mAb, monoclonal antibody; p24, p24, Borna disease virus phosphoprotein.

brain regions: Cerebral cortex, hippocampus and cerebellum. p24 is has been demonstrated to exhibit strong positive staining in the cytoplasm and weak staining in the nucleus; $\mathrm{p} 40$ has been demonstrated to exhibit strong positive staining in the nucleus and weak staining in the cytoplasm (35). Positive staining was graded according to the intensity and proportion. For intensity: 0 , no positive cells; 1 , light yellow; 2 , brown-yellow; and 3 , tan. For proportion: 0 , no positive cells; $1,1-25 \% ; 2,26-50 \% ; 3$, $51-75 \%$; and 4, 76-100\% (36).

Statistical analysis. A total of 10 representative areas were selected under a high magnification field (x400) for each slide. The mean intensity score was multiplied by the mean proportion score to produce the total score under all the dilution levels of the four primary antibodies, for BDV-infected and uninfected (negative control and normal control) groups,
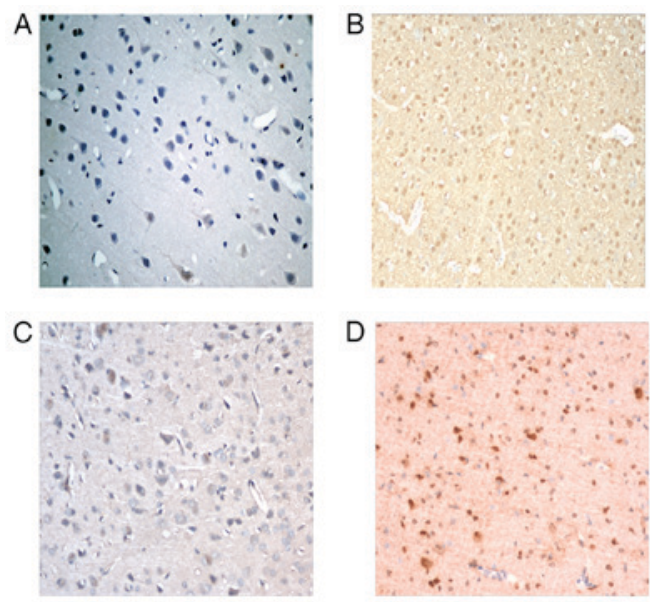

Figure 6. Immunohistochemical staining of BDV p40 protein in rat brain tissues (magnification, $\mathrm{x} 200$ ). Horseradish peroxidase-conjugated secondary antibodies and diaminobenzidine were used. Primary antibodies were diluted 1:200. (A) Negative results of tissue staining with pAbp40 from PBS-injected rats; (B) positive staining of tissue from the BDV-infected group with pAbp40, demonstrating that protein $\mathrm{p} 40$ was prominently expressed in the nucleus of neuronal and glial cells; (C) negative results of tissue staining with mAbp40; (D) positive staining of tissue from the BDV-infected group with mAbp40, demonstrating that protein $\mathrm{p} 40$ was prominently expressed in the nucleus of neuronal and glial cell. BDV, Borna disease virus; pAb, polyclonal antibody; $\mathrm{mAb}$, monoclonal antibody; $\mathrm{p} 40$, Borna disease virus nucleoprotein.

respectively. The total scores between the two groups were tested using the non-parametric Mann-Whitney test in SPSS (version 21.0; IBM Corp., Armonk, NY, USA). Data are presented as the mean \pm standard deviation. $\mathrm{P}<0.05$ was considered to indicate a statistically significant difference.

\section{Results}

Viral infection. The infection of $20 \mathrm{BDV}$-infected rats were confirmed by western blotting with monoclonal anti-p24 antibody (kindly provided by Professor Hanns Ludwig) (Fig. 1).

Purification of recombinant proteins. The purity of the recombinant p24 and p40 were analyzed by SDS-PAGE on a $12 \%$ gel (Fig. 2). The recombinant protein was primarily expressed in soluble form and purified by affinity chromatography. The band of His-p24 was $24 \mathrm{kDa}$ with a purity of $85 \%$, and the band of His-p40 appeared at $\sim 40 \mathrm{kDa}$ with a purity of $90 \%$. Results were confirmed by western blotting with monoclonal antibodies against p24 and p40, respectively (donated by Professor Hanns Ludwig), and the reaction bands were observed at 24 and $40 \mathrm{kDa}$. The results of western blotting demonstrated that the purified recombinant p24 or p40 protein was specifically bound to the monoclonal antibody. It was, therefore, immunologically confirmed that the expressed recombinant proteins had the correct antigenic activity and were able to be used to detect the antibody constructed.

Titer of antibodies. Positive dilutions were determined when the absorbance ratio of antibodies to the negative control was $>2: 1$ (Fig. 3). The data demonstrated that the titer of the polyclonal anti-p24 antibody was 1:128,000, as well as the monoclonal antibody. The titer of polyclonal and monoclonal anti-p40 antibody was 1:256,000 and 1:128,000, respectively. 
Western blot analysis. Western blot analysis demonstrated that proteins from BDV-infected OL cells and recombinant proteins were detected positively by pAbp24, mAbp24, pAbp40 and mAbp40 (Fig. 4). All normal OL cells exhibited no signal. Pre-immunization sera were used as the control, instead of primary antibodies, and there was no signal for either the recombinant or native proteins (data not shown). The results showed that the four antibodies had a good specificity for BDV p24 and p40, respectively.

Immunohistochemical analysis. The results of the four primary antibodies (pAbp24, mAbp24, pAbp40 and mAbp40) were positive in the BDV-infected group $(n=20)$ and were negative in the BDV-uninfected group $(n=60)$ (Figs. 5 and 6). For polyclonal anti-p24 and anti-p40 antibodies, the dilutions of 1:100 to 1:400 obtained strong positive staining with slight background coloring, and were therefore considered to be a suitable dilution. For monoclonal anti-p24 and anti-p40 antibodies, the dilutions of 1:200 to $1: 400$ obtained strong positive staining without background coloring, and were therefore considered to be a suitable dilution. The total mean scores for the four antibodies were 8 (mean) and 0 (mean) in BDV-infected and uninfected group, respectively. $\mathrm{P}$-values $(\mathrm{P}=0.000)$ were generated by the nonparametric Mann-Whitney test between the BDV-infected and uninfected group and the mean \pm standard deviation of the BDV-infected group was $7.38 \pm 3.59$, and $0.07 \pm 0.28$ for the uninfected group.

\section{Discussion}

There are no commercially available antibodies for BDV p24 and p40 on the market. In the present study, recombinant full-length BDV p24 and p40 were used as antigens to immunize rabbits and mice. Antibodies usually only recognize specific epitopes with conformational structures. Since in western blotting the antigen is denatured into a linear structure, this may lead to different results compared with methods using the conformational antigen and antibody $(37,38)$. The issue of conformational epitopes on BDV-p24/p40 has been addressed. The conformational epitopes of the donated monoclonal antibodies used in the present study and their characterization have been examined previously $(31,39)$. However, the conformational epitopes of the antibodies against recombinant proteins produced in the present study remain to be elucidated, and further analysis is required. However, the high specificity and sensitivity of the four antibodies produced in the present study were confirmed by western blotting, ELISA analysis and immunohistochemistry on paraffin sections.

Analysis of BDV protein expression (particularly p24/p40) in human brain tissue may determine BDV infection in humans; however, this method is unsuitable for epidemiological screening due to the low viral titer in patients and the necessity for time-consuming surgery. Serum or plasma samples are the easiest diagnostic sources and infection may be determined by easily accessible blood samples. As BDV is a highly neurotropic virus, brain tissue represents an ideal sample source to detect BDV infection. Researchers have observed BDV RNA and antigens in the brains of patients with neuropsychiatric disorders $(14,40)$. Clinical human brain tissue samples are frequently stored in paraffin blocks; therefore, it may be convenient to detect BDV infection in these samples by immunohistochemistry, and to study the correlation between BDV infection and morbidity (40).

Compared with the polyclonal antibodies in the present study, the sensitivity of the monoclonal antibodies was consistent and the specificity was increased; additionally, the nonspecific staining of the background was decreased with the monoclonal antibodies. The results of the present study demonstrated that the polyclonal and monoclonal anti-p24 and anti-p40 antibodies against recombinant proteins were highly specific and sensitive for BDV p24 and p40 detection, and may be efficiently used to detect BDV infection in paraffin sections of human brain tissue in future studies.

\section{Acknowledgements}

The authors of the present study would like to thank Professor Liv Bode and Professor Hanns Ludwig of the Robert Koch Institute and Institute of Virology at the Free University of Berlin (Berlin, Germany) for providing the human oligodendroglioma cell line and the Borna disease virus strain $\mathrm{Hu}-\mathrm{H} 1$ used in the present study. The present study was supported by the National Basic Research Program of China (973 Program) (grant no. 2009CB918300) and the Natural Science Foundation of Chongqing City of China (grant no. cstc2013jcyjA10003).

\section{References}

1. Ludwig $\mathrm{H}$ and Bode L: Borna disease virus: New aspects on infection, disease, diagnosis and epidemiology. Rev Sci Tech 19: 259-288, 2000.

2. Gonzalez-Dunia D, Sauder C and de la Torre JC: Borna disease virus and the brain. Brain Res Bull 44: 647-664, 1997.

3. Kuhn JH, Dürrwald R, Báo Y, Briese T, Carbone K, Clawson AN, deRisi JL, Garten W, Jahrling PB, Kolodziejek J, et al: Taxonomic reorganization of the family Bornaviridae. Arch Virol 160: 621-632, 2015.

4. Waltrip RW II, Buchanan RW, Summerfelt A, Breier A, Carpenter WT Jr, Bryant NL, Rubin SA and Carbone KM: Borna disease virus and schizophrenia. Psychiatry Res 56: 33-44, 1995.

5. Bode L, Dürrwald R, Rantam FA, Ferszt R and Ludwig H: First isolates of infectious human Borna disease virus from patients with mood disorders. Mol Psychiatry 1: 200-212, 1996.

6. Zhang L, Xu MM, Zeng L, Liu S, Liu X, Wang X, Li D, Huang RZ, Zhao LB, Zhan QL, et al: Evidence for Borna disease virus infection in neuropsychiatric patients in three western China provinces. Eur J Clin Microbiol Infect Dis 33: 621-627, 2014.

7. Bode L and Ludwig H: Borna disease virus infection, a human mental-health risk. Clin Microbiol Rev 16: 534-545, 2003.

8. Ikuta K, Ibrahim MS, Kobayashi T and Tomonaga K: Borna disease virus and infection in humans. Front Biosci 7: d470-d495, 2002.

9. Wang X, Zhang L, Lei Y, Liu X, Zhou X, Liu Y, Wang M, Yang L, Zhang L, Fan S and Xie P: Meta-analysis of infectious agents and depression. Sci Rep 4: 4530, 2014.

10. Zaliunaite V, Steibliene V, Bode L, Podlipskyte A, Bunevicius R and Ludwig H: Primary psychosis and Borna disease virus infection in Lithuania: A case control study. BMC Psychiatry 16: 369, 2016.

11. Donfrancesco R, Gregori P, Vulcano A, Candelori E, Ronchetti R, Miano S, Pagani J, Villa MP and Patti AM: Borna disease virus infection in children with psychiatric disorders. APMIS Suppl: 80-82, 2008.

12. Nakaya T, Tada M, Takahashi H, FUJIWAR S, SAKUMA S, SAWAMUR Y, ABE H and IKUTA K: Expression of borna disease virus messages in clinical samples from patients with brain malignant tumors. Proc Japan Academy Ser B Physl Biol Sci 72: 157-162, 1996. 
13. Salvatore M, Morzunov S, Schwemmle M and Lipkin WI: Borna disease virus in brains of North American and European people with schizophrenia and bipolar disorder. Bornavirus Study Group. Lancet 349: 1813-1814, 1997.

14. Nakamura Y, Takahashi H, Shoya Y, Nakaya T, Watanabe M, Tomonaga K, Iwahashi K, Ameno K, Momiyama N, Taniyama $\mathrm{H}$, et al: Isolation of Borna disease virus from human brain tissue. J Virol 74: 4601-4611, 2000.

15. Haga S, Yoshimura M, Motoi Y, Arima K, Aizawa T, Ikuta K, Tashiro $\mathrm{M}$ and Ikeda K: Detection of Borna disease virus genome in normal human brain tissue. Brain Res 770: 307-309, 1997.

16. Takahashi H, Nakaya T, Nakamura Y, Asahi S, Onishi Y, Ikebuchi K, Takahashi TA, Katoh T, Sekiguchi S, Takazawa M, et al: Higher prevalence of Borna disease virus infection in blood donors living near thoroughbred horse farms. J Med Virol 52: 330-335, 1997.

17. Ludwig H, Bode L and Gosztonyi G: Borna disease: A persistent virus infection of the central nervous system. Prog Med Virol 35: $107-151,1988$

18. Bode L, Zimmermann W, Ferszt R, Steinbach F and Ludwig H: Borna disease virus genome transcribed and expressed in psychiatric patients. Nat Med 1: 232-236, 1995.

19. Lipkin W and Briese T: Bornaviridae. In: Fields Virology. Vol 2. 5th edition. Knipe D HP, Griffin D, Lamb R, Martin M, Roizman B, Straus S (eds). Lippincott, Williams \& Wilkins, Philadelphia: pp1829-1851, 2007.

20. Bode L, Reckwald P, Severus WE, Stoyloff R, Ferszt R, Dietrich DE and Ludwig H: Borna disease virus-specific circulating immune complexes, antigenemia and free antibodies-the key marker triplet determining infection and prevailing in severe mood disorders. Mol Psychiatry 6: 481-491, 2001.

21. Mazaheri-Tehrani E, Maghsoudi N, Shams J, Soori H, Atashi H, Motamedi F, Bode L and Ludwig H: Borna disease virus (BDV) infection in psychiatric patients and healthy controls in Iran. Virol J 11: 161, 2014.

22. Flower RL, Kamhieh S, McLean L, Bode L, Ludwig H and Ward CM: Human Borna disease virus infection in Australia: Serological markers of infection in multi-transfused patients. Apmis Suppl: 89-93, 2008.

23. Liu X, Bode L, Zhang L, Wang X, Liu S Zhang L, Huang R, Wang M, Yang L, Chen S, et al: Health care professionals at risk of infection with Borna disease virus-evidence from a large hospital in China (Chongqing). Virol J 12: 39, 2015.

24. Miranda HC, Nunes SO, Calvo ES, Suzart S, Itano EN and Watanabe MA: Detection of Borna disease virus p24 RNA in peripheral blood cells from Brazilian mood and psychotic disorder patients. J Affect Disord 90: 43-47, 2006.

25. Rott R, Herzog S, Fleischer B, Winokur A, Amsterdam J, Dyson W and Koprowski H: Detection of serum antibodies to Borna disease virus in patients with psychiatric disorders. Science 228: 755-756, 1985.

26. Fu ZF, Amsterdam JD, Kao M, Shankar V, Koprowski H and Dietzschold B: Detection of Borna disease virus-reactive antibodies from patients with affective disorders by western immunoblot technique. J Affect Disord 27: $61-68,1993$
27. Sauder C, Müller A, Cubitt B, Mayer J, Steinmetz J, Trabert W, Ziegler B, Wanke K, Mueller-Lantzsch N, de la Torre JC and Grässer FA: Detection of Borna disease virus (BDV) antibodies and BDV RNA in psychiatric patients: Evidence for high sequence conservation of human blood-derived BDV RNA. J Virol 70: 7713-7724, 1996.

28. Dietzel J, Kuhrt H, Stahl T, Kacza J, Seeger J, Weber M, Uhlig A, Reichenbach A, Grosche A and Pannicke T: Morphometric analysis of the retina from horses infected with the Borna disease virus. Vet Pathol 44: 57-63, 2007.

29. Horimoto T, Takahashi H, Sakaguchi M, Horikoshi K, Iritani S, Kazamatsuri H, Ikeda K and Tashiro M: A reverse-type sandwich enzyme-linked immunosorbent assay for detecting antibodies to Borna disease virus. J Clin Microbiol 35: 1661-1666, 1997.

30. Nakamura Y, Watanabe M, Kamitani W, Taniyama H, Nakaya T, Nishimura Y, Tsujimoto H, Machida S and Ikuta K: High prevalence of Borna disease virus in domestic cats with neurological disorders in Japan. Vet Microbiol 70: 153-169, 1999.

31. Ludwig H, Furuya K, Bode L, Klein N, Dürrwald R and Lee DS: Biology and neurobiology of Borna disease viruses (BDV), defined by antibodies, neutralizability and their pathogenic potential. Arch Virol Suppl 7: 111-133, 1993.

32. Lei Y, Li D, Deng J, Shao WH, Fan SH, Wang X, Huang H, Chen SG, Zhang HZ, Zhang L, et al: Metabolomic profiling of three brain regions from a postnatal infected Borna disease virus Hu-H1 rat model. Metabolomics 10: 484-495, 2014.

33. Chen CH, Chiu YL, Wei FC, Koong FJ, Liu HC, Shaw CK, Hwu HG and Hsiao KJ: High seroprevalence of Borna virus infection in schizophrenic patients, family members and mental health workers in Taiwan. Mol Psychiatry 4: 33-38, 1999.

34. Gosztonyi $\mathrm{G}$ and Ludwig H: Borna disease-neuropathology and pathogenesis. Curr Top Microbiol Immunol 190: 39-73, 1995

35. Kamitani W, Ono E, Yoshino S, Kobayashi T, Taharaguchi S, Lee BJ, Yamashita M, Kobayashi T, Okamoto M, Taniyama $\mathrm{H}$, et al: Glial expression of Borna disease virus phosphoprotein induces behavioral and neurological abnormalities in transgenic mice. Proc Natl Acad Sci USA 100: 8969-8974, 2003.

36. Iizasa T, Chang H, Suzuki M, Otsuji M, Yokoi S, Chiyo M, MotohashiS, Yasufuku K, Sekine Y,Iyoda A, et al: Overexpression of collagen XVIII is associated with poor outcome and elevated levels of circulating serum endostatin in non-small cell lung cancer. Clin Cancer Res 10: 5361-5366, 2004.

37. Billich C, Sauder C, Frank R, Herzog S, Bechter K, Takahashi K, Peters H, Staeheli P and Schwemmle M: High-avidity human serum antibodies recognizing linear epitopes of Borna disease virus proteins. Biol Psychiatry 51: 979-987, 2002.

38. Matsunaga H, Tanaka S, Sasao F, Nishino Y, Takeda M, Tomonaga $\mathrm{K}$, Ikuta $\mathrm{K}$ and Amino N: Detection by radioligand assay of antibodies against Borna disease virus in patients with various psychiatric disorders. Clin Diagn Lab Immunol 12: 671-676, 2005.

39. Bode L: Human bornavirus infection- towards a valid diagnostic system. APMIS Suppl: 21-39, 2008.

40. De La Torre JC, Gonzalez-Dunia D, Cubitt B, Mallory M, Mueller-Lantzsch N, Grässer FA, Hansen LA and Masliah E: Detection of borna disease virus antigen and RNA in human autopsy brain samples from neuropsychiatric patients. Virology 223: 272-282, 1996. 